\title{
Effects of the Age-Related Resistance to Potato virus $Y$ in Potato on the Systemic Spread of the Virus, Incidence of the Potato Tuber Necrotic Ringspot Disease, Tuber Yield, and Translocation Rates Into Progeny Tubers
}

\author{
Mohamad Chikh-Ali, ${ }^{1}$ Lisa T. Tran, ${ }^{1}$ William J. Price, ${ }^{2}$ and Alexander V. Karasev ${ }^{1,3, \dagger}$ \\ ${ }^{1}$ Department of Entomology, Plant Pathology, and Nematology, University of Idaho, Moscow, ID 83844-2329 \\ ${ }^{2}$ Statistical Programs, College of Agricultural and Life Sciences, Moscow, ID 83844-2337 \\ ${ }^{3}$ Bioinformatics and Computational Biology Program, University of Idaho, Moscow, ID 83844-3050
}

\begin{abstract}
The recombinant strain of potato virus $\mathrm{Y}$ (PVY), PVY ${ }^{\mathrm{NTN}}$, is the main cause of the potato tuber necrotic ringspot disease (PTNRD) in susceptible potato cultivars, which reduces the quality of potato tubers, in addition to the yield loss. Control of PVY has been the main challenge in most potato-producing areas. Here, the effects of the age-related resistance (ARR) were investigated in transplants of a potato cultivar Yukon Gold to the infection with PVYNTN strain in greenhouse experiments. Within the first 3 weeks after transplanting into soil (week 1 [W1] to W3), Yukon Gold plants developed ARR that impaired the systemic movement of $\mathrm{PVY}^{\mathrm{NTN}}$ into upper noninoculated leaves and concomitant translocation into progeny tubers starting from W4 after transplanting. The yield and

production. Plants inoculated early (W1 to W2), before the establishment of the ARR, exhibited a $100 \%$ primary systemic infection with PVY ${ }^{\text {NTN }}$ and produced fewer tubers of smaller sizes, exhibiting PTNRD; this resulted $\leq 70 \%$ yield reduction compared with plants inoculated later in the season (W5 to W8). This ARR greatly restricted the systemic movement of PVY ${ }^{\text {NTN }}$ in the foliage and resulted in very limited translocation rates of the virus into tested progeny tubers: 7.8 and $4.1 \%$ in 2017 and 2018, respectively, of all plants inoculated later in the season (W5 to W8). This study suggests that PVY ${ }^{\mathrm{NTN}}$ management programs in Yukon Gold seed potato should focus more on the early stages of the potato development before the onset of the ARR.
\end{abstract} quality of tubers from PVY-infected plants with the established ARR (W5 to W8) were comparable with the healthy controls, suggesting that late PVY infection would not significantly affect commercial potato
Keywords: age-related resistance, disease management, cultivar/ resistance, PTNRD, PVY ${ }^{\text {NTN }}$, vegetables, viruses and viroids
Potato virus Y (PVY) is the type species of the genus Potyvirus, family Potyviridae; it is the most economically important and devastating virus infecting cultivated potato (Solanum tuberosum) crops worldwide (Gray et al. 2010; Karasev and Gray 2013; Quenouille et al. 2013; Singh et al. 2008). PVY affects both potato tuber yield and quality (Beczner et al. 1984; Nolte et al. 2004; Rosenman et al. 2019), and its control has proven to be a challenge owing to the complex strain composition, the nonpersistent transmissibility by many aphid species, vegetative propagation and extensive trade in seed potato tubers, and the difficulties associated with breeding for PVY-resistant cultivars (Karasev and Gray 2013; Singh et al. 2008). Currently, PVY is a major cause of the degeneration of seed potatoes, which requires a regular flushing out of seed potatoes after limited field production cycles (Frost et al. 2013; Gray and Power 2018).

Because of the significance of the virus, potato resistance to PVY has been studied for a long time, and various resistance types have been identified in cultivated and wild potatoes, including extreme resistance (ER), hypersensitivity, and field resistance, that interfere with PVY infection at different levels (Davidson 1980; Jones 1990; Solomon-Blackburn and Barker 2001a, b; Valkonen 1994; Valkonen et al. 1996). In potato breeding programs, two major

${ }^{\dagger}$ Corresponding author: A. V. Karasev; akarasev@uidaho.edu

Funding: This work was funded in part by USDA-NIFA-SCRI grant 201451181-22373; USDA-ARS grants 58-5354-7-540, 58-5354-2-345, and 581907-8-870; the Northwest Potato Research Consortium; Idaho Potato Commission; the USDA-NIFA Hatch Project grant IDA01560; and the Idaho Agricultural Experiment Station.

The author(s) declare no conflict of interest.

Accepted for publication 9 August 2019.

@) 2020 The American Phytopathological Society resistance sources have been deployed on a limited scale so far, which are identified as effector-triggered $N$ and $R$ resistance genes. In potato cultivars with the $N$ resistance genes, PVY infection induces hypersensitive response (HR) in a strain-specific manner, which restricts the systemic movement of the target strain within potato plants (Cockerham 1970; Funke et al. 2017; Jones 1990; Jones and Vincent 2018; Kehoe and Jones 2016; Rowley et al. 2015; Solomon-Blackburn and Barker 2001a, b). Multiple $N$ resistance genes have been identified in cultivated potato, including $N y_{t b r}, N c_{t b r}$, and $N z_{t b r}$ specific of the strains $\mathrm{PVY}^{\mathrm{O}}, \mathrm{PVY}^{\mathrm{C}}$, and $\mathrm{PVY}{ }^{\mathrm{Z}}$ (including the recombinant $P V Y^{N T N}$ ), respectively (Chikh-Ali et al. 2014; Cockerham 1970; De Bokx and Huttinga 1981; Jones 1990; Jones and Vincent 2018; Kerlan et al. 2011; Rowley et al. 2015). In a 2016 study, the putative $N d$ resistance gene was proposed as a specific resistance gene of the newly described strain $\mathrm{PVY}^{\mathrm{D}}$ (Kehoe and Jones 2016). The strain-specific nature of the $N$ resistance genes to PVY compromises the efficiency of their protective effect in potato and drives the shifts in PVY strain composition in the field (Dupuis et al. 2019; Funke et al. 2017). However, $R$ genes conferring ER or immunity to PVY infection were identified in three wild potato species: $R y_{\text {sto }}$ in Solanum stoloniferum (Cockerham 1970), $R y_{\text {adg }}$ in S. tuberosum subsp. andigena (Munoz et al. 1975), and $R y_{\text {chc }}$ in Solanum chacoense (Asama et al. 1982). These three $R y$ genes were adopted by potato breeding programs, leading to releases of potato cultivars exhibiting ER to PVY infection, such as cultivar Payette Russet carrying the $R y_{\text {sto }}$ resistance gene (Novy et al. 2017). Over time, this may lead to control over the PVY spread if $R y$-bearing cultivars become widely accepted by the industry and dominant in potato production areas. Unfortunately, until this happens, other methods to control PVY spread in potato fields need to be found.

Another potential source of resistance to plant pathogens is the age-related resistance (ARR) identified in many hosts, such as Arabidopsis thaliana, Nicotiana benthamiana, and sugar beet, to various pathogens, including the bacteria Pseudomonas syringa (Kus et al. 2002; Wilson et al. 2017), the oomycete Phytophthora infestans (Shibata et al. 2010), and the fungus Rhizoctonia solani (Liu et al. 
2019). Generally, ARR can be defined by the changes in the resistance of whole plants or plant tissues to plant pathogens in correlation with plant development (Panter and Jones 2002) or by the increased resistance or reduced susceptibility of the older leaves or plants to pathogens compared with the younger leaves or plants (DeveleyRivière and Galiana 2007; Hu and Yang 2019). ARR required the activation of signal transduction pathways mediated by phytohormones, like salicylic acid and ethylene (Develey-Rivière and Galiana 2007; Kus et al. 2002; Shibata et al. 2010; Wilson et al. 2017). In potato, the ARR, referred to as the mature plant resistance (MPR), was described and studied for many European potato cultivars against PVY strains, demonstrating development of the MPR through reduced and blocked systemic movement of the virus and translocation into the progeny tubers starting at 3 to 4 weeks after emergence (Beemster 1976; Dupuis 2017; Gibson 1991; Sigvald 1985). Although the mechanism underlying this MPR was not defined in potato-PVY pathosystem, this phenomenon had a potential to control PVY spread by aphids, particularly late in the growing season (Dupuis 2017; Gibson 1991). The effectiveness of the MPR was not addressed in North American potato cultivars.

In North America, the ordinary, nonrecombinant $\mathrm{PVY}^{\mathrm{O}}$ strain of the virus remained dominant among the PVY isolates circulating in potato fields until 2012 (Baldauf et al. 2006; Funke et al. 2017; Gray et al. 2010; MacKenzie et al. 2018, 2019), although several PVY strains were reported from potato, including $\mathrm{PVY}^{\mathrm{O}}, \mathrm{PVY}^{\mathrm{O}-\mathrm{O} 5}$, $\mathrm{PVY}^{\mathrm{N}}, \mathrm{PVY}^{\mathrm{NA}-\mathrm{N}}$, PVY-NE11, PVY ${ }^{\mathrm{N}: \mathrm{O}}, \mathrm{PVY}^{\mathrm{N}-\mathrm{Wi}}$, and PVY ${ }^{\mathrm{NTN}}$ (Funke et al. 2017; Gray et al. 2010; Green et al. 2018; Karasev and Gray 2013; Lorenzen et al. 2008; Piche et al. 2004). However, the prevalence of these strains changed dramatically after 2012, with reports revealing the expansion of the recombinant strains $\mathrm{PVY}^{\mathrm{N}-\mathrm{Wi}}$ and $\mathrm{PVY}^{\mathrm{NTN}}$ at the expense of the ordinary strain $\mathrm{PVY} \mathrm{Y}^{\mathrm{O}}$, probably because of the deployment of the strain-specific $N$ resistance genes in potato cultivars (Funke et al. 2017). Other strains, such as $\mathrm{PVY}^{\mathrm{N}}$ and PVY ${ }^{\mathrm{NA}-\mathrm{N}}$, are rarely encountered in potato fields in North America (Funke et al. 2017; Gray et al. 2010; Green et al. 2018; MacKenzie et al. 2018, 2019).

PVY ${ }^{\mathrm{NTN}}$ is a major cause of potato tuber necrotic ringspot disease (PTNRD), which dramatically affects the quality of potato tubers and reduces their marketability. PTNRD was first reported from Hungary in the early 1980s (Beczner et al. 1984), and soon thereafter, it became epidemic throughout Europe (Le Romancer et al. 1994; van den Heuvel et al. 1994). In Canada, an isolate was identified as PVY $^{\text {NTN }}$ for the first time in 1991 based on its ability to induce PTNRD (McDonald and Singh 1996). That isolate was collected from table potato tubers produced in California from seed potatoes originating from Canada (Gray et al. 2010). PVY ${ }^{\mathrm{NTN}}$ was first reported in the United States in 2002, although it is believed that this strain was there earlier (Crosslin et al. 2002; Gray et al. 2010). In North America, potato cultivars vary in their sensitivity to PTNRD, with the cultivar Yukon Gold being the most sensitive cultivar that is used routinely as an indicator of PTNRD (Gray et al. 2010).

To address the effects of the ARR on the recombinant strain $\mathrm{PVY}^{\mathrm{NTN}}$ in Yukon Gold, several experiments were conducted under greenhouse conditions. Here, we investigated the relationships between the age of Yukon Gold plants at the time of PVY infection and (i) the rates of primary systemic infection, (ii) the incidence and severity of PTNRD, (iii) the tuber yield, (iv) the virus translocation rates into progeny tubers, and (v) the rates of secondary infection from primarily infected tubers. The data obtained suggested that the ARR may be an effective means to control PVYNTN infection in Yukon Gold at later stages of the potato plant development.

\section{Materials and Methods}

PVY isolate, potato cultivar, and growing conditions. The $\mathrm{PVY}^{\mathrm{NTN}}$ isolate HR1 and the PTNRD-susceptible potato Yukon Gold were used in this study. HR1 (GenBank accession number FJ204166) was originally isolated from a potato tuber with PTNRD collected from southern Idaho in 2007 (Karasev et al. 2008). Since then, this isolate was maintained in tobacco (Nicotiana tabacum 'White Burley') in a climate-controlled, insect-free growth chamber as described previously (Karasev et al. 2010). The infection status of tobacco and potato plants was confirmed by triple-antibody sandwich enzyme-linked immunosorbent assay (TAS-ELISA) using a series of PVY-specific polyclonal and monoclonal antibodies as described (Funke et al. 2017; Nikolaeva et al. 2012) and immunocapture reverse transcription PCR (IC-RT-PCR) (Chikh-Ali et al. 2013a).

Virus-free tissue culture-propagated plantlets of Yukon Gold were planted in a gallon pot of sunshine potting soil mix with slow release fertilizer (Ozmocote), and they were allowed to grow in a greenhouse. Growing conditions were set at temperature range of 22 to $24^{\circ} \mathrm{C}$ for day and 14 to $18^{\circ} \mathrm{C}$ for night, with 16 -h day, 8-h night, and natural light conditions from May to August of 2017 and 2018.

Experimental design. A randomized block design was used with three blocks and nine treatments. Treatments in each block consisted of sets of five plants inoculated every week starting from week 1 (W1) and going to W8 after transplanting in addition to one noninoculated set of five plants left as a healthy control. This experiment was repeated twice during 9 May to 15 August 2017 and 8 May to 9 August 2018 to mimic the natural growing season in Idaho.

Mechanical inoculation and testing for systemic infection. Three replicates of five plants each were inoculated weekly from W1 to W8 after transplanting. To have a consistent inoculum source, Yukon Gold plants were inoculated with HR1 isolate at 2 weeks after transplanting and used 3 to 4 weeks later as inoculation. To prepare the inoculum, fresh symptomatic PVY ${ }^{\mathrm{NTN}}$-positive leaves (as confirmed by IC-RT-PCR) were ground in a phosphate buffer $(50 \mathrm{mM}$ sodium phosphate, $\mathrm{pH}$ 7.0) at dilution rate 1:10 (wt/vol). The inoculum was also tested by PVY immunostrips (Agdia) and then, used immediately for the inoculation. On each plant, three leaflets (typically the leaves three to five from the top) were marked and inoculated. When multiple stems on the same plant were encountered, at least one leaflet per stem was inoculated. To test and confirm the inoculum infectivity, young $N$. benthamiana plants were inoculated at the same time with each weekly potato set.

To test for systemic infection, inoculated (one per plant) and upper noninoculated leaflets (three per plant) on each inoculated plant were sampled and tested for PVY infection using TAS-ELISA and IC-RTPCR as described previously (Chikh-Ali et al. 2013a, b; Nikolaeva et al. 2012). In the experiment of 2017, plants were tested for PVY primary infection only once at 3 weeks after the last inoculation (W8). However, by that time, plants inoculated at W1 to W3 were killed by PVY infection and could not be tested. Therefore, to avoid this in 2018, each weekly inoculation set was tested separately 4 weeks postinoculation.

Scoring for PTNRD, tuber number, and yield. At $\sim 12$ weeks posttransplanting, the foliage of each plant was pulled out, and a week later, the tubers were harvested from each plant and examined for the expression of PTNRD initially at harvest. For each plant, total tuber number, number of PTNRD-positive tubers, number of necrotic rings/arcs per tuber, and tuber weight were recorded. Tubers from each plant were kept separately in a clothes bag and stored in a dark place at room temperature. At 1 month after harvest, the tubers were scored for PTNRD expression again.

Testing of secondarily infected plants. Approximately 3 months after harvest, two sprouting tubers harvested from the same plant were planted in 4-inch pots with a total of 30 tubers per inoculation week, and they were allowed to grow under greenhouse conditions with 16-h day/8-h night and temperature of $22^{\circ} \mathrm{C}$. PTNRD symptoms were scored for each tuber at planting time. The selection of a tuber for planting was partially based on the presence of rings or arcs associated with PTNRD. If PTNRD symptoms were present, these tubers were selected for the secondary infection testing; if no PTNRD symptoms were present, tubers were selected randomly. Six to seven weeks after planting, young emerging plants were scored for systemic foliar symptoms and tested for systemic infection using PVY-specific TAS-ELISA and IC-RT-PCR to determine possible tuberborne, systemic PVY infection.

Statistical analysis. The effects of plant age on PVY primary systemic infection, progeny tuber counts, PTNRD severity, and yield 
were assessed using a generalized linear mixed model with treatments (plant age at inoculation) as fixed effects and blocks and plants as random effects assuming a binomial distribution for primary infection, a Poisson distribution for tuber counts, a log-normal distribution for severity, and a Gaussian distribution for yield. Differences within significant treatment effects were determined through pairwise comparisons of least square means $(\alpha=0.05)$. All statistical analyses were carried out using SAS 9.4 (Proc Glimmix; SAS Institute Inc.).

\section{Results}

The effects of plant age at inoculation on PVY primary and secondary infections. For both 2017 and 2018 experiments, the negative noninoculated controls showed no symptoms in foliage, and they were found negative for systemic PVY infection. Plants inoculated with PVY ${ }^{\text {NTN }}$ at W1 to W4 developed local and systemic necrotic reactions typical of $\mathrm{HR}$, consisting of yellowing, necrotic spots/rings, vein necrosis, and lower leaf drop accompanied with mottle on the upper leaves (Fig. 1). PVY ${ }^{\mathrm{NTN}}$ was detected in inoculated and noninoculated upper leaves in plants inoculated at W1 to W3 and most upper noninoculated leaves of plants inoculated at W4 (Fig. 2). Foliage for most of these plants was dead about 2 months after inoculation, whereas a few plants lasted longer but looked stunted, particularly those of W1 to W3 (Fig. 1). Plants inoculated at W5 to W8 developed local necrotic reactions on inoculated leaves that are typical of HR followed by the death of the inoculated leaflets, similar to earlier weeks of inoculation (Fig. 1). PVY ${ }^{\text {NTN }}$ was easily detected in inoculated leaves until their full necrotization, but it was rarely detected in the upper noninoculated leaves for these W5
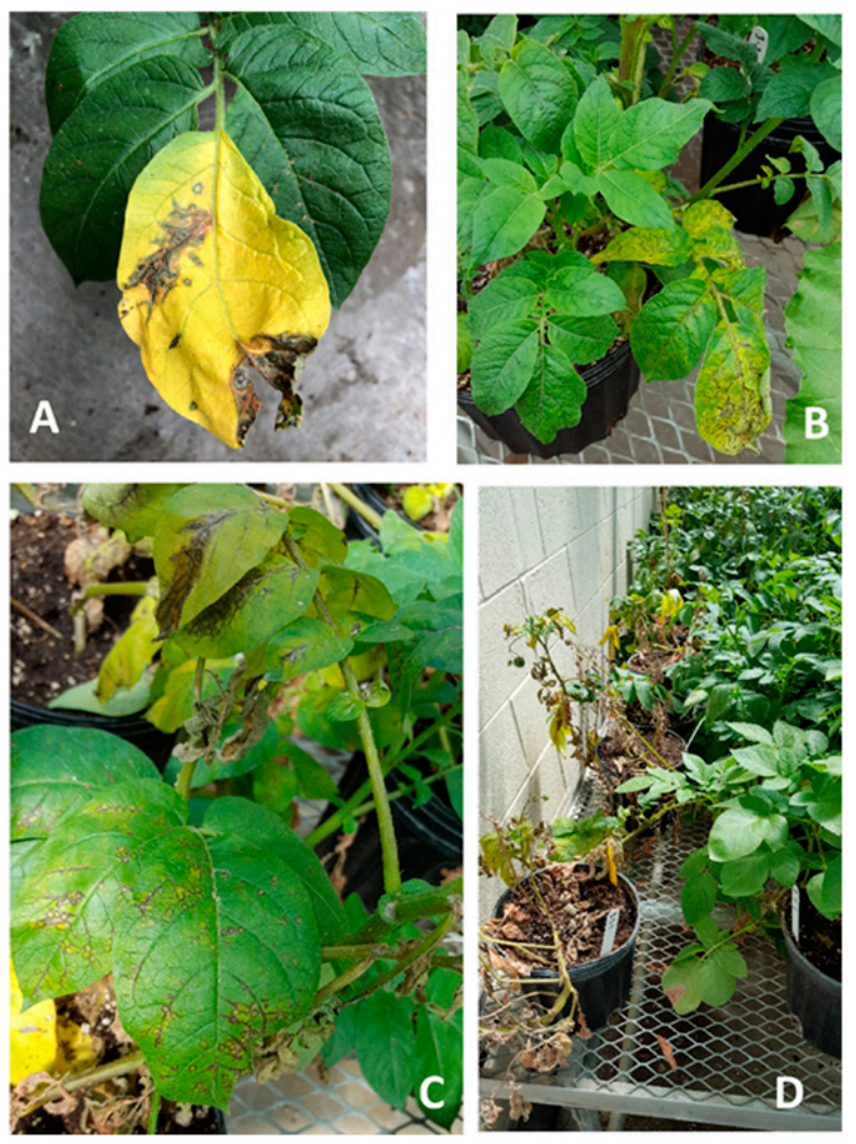

Fig. 1. Plants of cultivar Yukon Gold displaying various types of symptoms on inoculation with an isolate of the recombinant strain of potato virus $Y$ (PVY), PVY NTN, at different ages after transplanting. A, Local hypersensitive resistance (HR) reaction resulted in wilting and dying of inoculated leaves. B, Systemic mottle and HR expressed as yellowing, necrotic rings and spots, and vein necrosis on upper noninoculated leaves. C, Severe HR symptoms on upper noninoculated leaves. D, Plants inoculated at 3 weeks after transplanting became dead by 6 weeks postinoculation compared with plants inoculated at a later age (right). to W8 plants (Fig. 2). In the 2018 experiment, for instance, PVY was detected in the inoculated leaves of 9 of 15 plants of W8, whereas only a single plant exhibited systemic PVY infection when the upper leaves were tested; in this single case, enzyme-linked immunosorbent assay signal (optical density at $405 \mathrm{~nm}, \mathrm{OD}_{405}$ ) exceeded the negative control only by twofold. It is worth mentioning that even this plant (W8 plant with upper noninoculated leaves positive for PVY) produced tubers without PTNRD, and two of these tubers, tested in a subsequent grow out, produced plants negative for systemic PVY infection.

The secondary (or tuberborne) infection showed a similar trend. In 2017 and 2018, all tubers from W1 and W2 plants produced PVYpositive plants (systemic secondary infection) (Table 1). The number of PVY-positive plants emerging from tubers harvested from plants inoculated at different time points declined starting from W4 and dropped to zero for W7. Only a single tuber produced a PVYpositive plant from inoculations at W8 in 2017 (Table 1). When the primary and secondary infections for $\mathrm{W} 4$ to $\mathrm{W} 8$ were compared in 2017, the upper leaves of 10 plants were found negative for PVY (no systemic infection) but produced at least one PVY-infected tuber. These included four plants of W4, four plants of W5, one plant of W6, and one plant of W8. In the case of W6 and W8, only a single tuber per plant was found PVY infected in a subsequent grow out. In 2018, only four plants were found negative for the primary PVY infection (no systemic infection) but produced PVY-positive tubers identified during the secondary infection testing. Of these four plants, two of the W4-infected plants produced PVY-infected tubers (both of the two tubers tested per plant), and the other two came from two

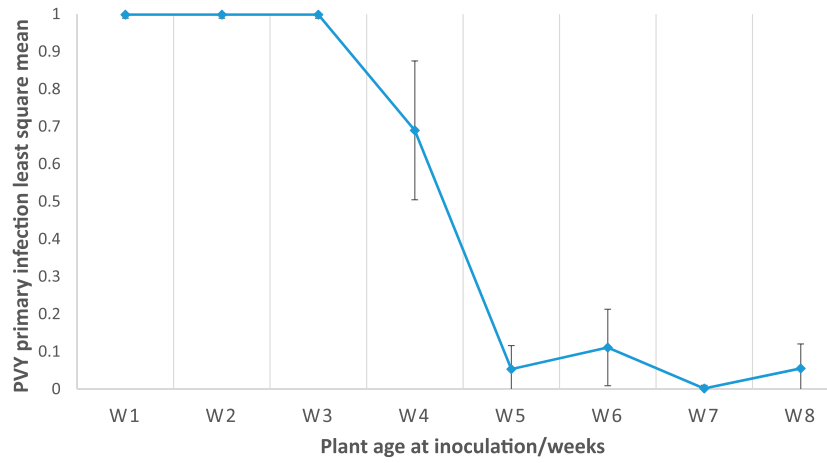

Fig. 2. The relationship between the mean rate of systemic primary infection of cultivar Yukon Gold ( $y$ axis) after the inoculation with the recombinant strain of potato virus $Y(P V Y), P V Y^{\text {NTN }}$, at 8 consecutive weeks (W1 to W8; $x$ axis) after transplanting in a greenhouse experiment in 2018. Upper noninoculated leaflets (three per plant) on each plant were tested for PVY 4 weeks after inoculation using triple-antibody sandwich enzyme-linked immunosorbent assay and immunocapture reverse transcription PCR as described previously (Chikh-Ali et al. 2013a, b; Nikolaeva et al. 2012). Data were analyzed using the GLIMMIX procedure (residual pseudo-likelihood). Each treatment (inoculation set) consisted of five plants and was replicated three times (three blocks).

Table 1. Numbers of systemically infected potato plants that emerged from tubers originating from plants inoculated with potato virus $\mathrm{Y}\left(\mathrm{PVY} \mathrm{YTN}^{\mathrm{NTN}}\right)$ at 8 different consecutive weeks after transplanting and two seasons of greenhouse experiments in 2017 and 2018

\begin{tabular}{lcc}
\hline $\begin{array}{l}\text { Plant age } \\
\text { at inoculation }^{\mathbf{a}}\end{array}$ & $\begin{array}{c}\text { Experiment } \\
\text { of 2017 }^{\mathbf{b}}\end{array}$ & $\begin{array}{c}\text { Experiment } \\
\text { of 2018 }^{\mathbf{b}}\end{array}$ \\
\hline W1 & $20 / 20$ & $25 / 25$ \\
W2 & $28 / 28$ & $21 / 21$ \\
W3 & $24 / 29$ & $25 / 26$ \\
W4 & $8 / 30$ & $17 / 30$ \\
W5 & $6 / 30$ & $2 / 30$ \\
W6 & $2 / 30$ & $3 / 30$ \\
W7 & $0 / 26$ & $0 / 30$ \\
W8 & $1 / 30$ & $0 / 30$ \\
Healthy & $0 / 30$ & $0 / 30$ \\
\hline a W, week after transplanting at which the inoculation was carried out.
\end{tabular}

b Total number of tubers that produced PVY-positive plants per total tubers planted. 
separate W6-infected plants, producing one PVY-infected tuber of the two tubers tested per plant. However, one plant each from W6and W8-infected plants was found to be PVY positive for the primary infection, but all of their tubers produced PVY-negative plants.

The effects of plant age at inoculation on tuber yield. Average tuber counts per plants showed the same trend in both years (2017 and 2018), with no significant effects of the year $(P r>F=$ $0.5167)$ or the year $\times$ week of inoculation $(\operatorname{Pr}>F=0.8213)$. However, the effect of the week of inoculation was significant $(\operatorname{Pr}>F=$ 0.0003 ). Plants of $\mathrm{W} 1$ and $\mathrm{W} 2$ inoculations had average tuber counts of 2.0 per plant, which increased significantly starting from $\mathrm{W} 3$ inoculations to about 4.0 tubers per plant (Fig. 3). No significant differences in tuber counts per plant were recorded for W3 to W8 inoculations compared with the healthy control (Fig. 3).

Average tuber yield per plant was significantly affected by the plant age at inoculation $(\operatorname{Pr}>F=0.0001)$ and the year of experiment $(\operatorname{Pr}>F=0.0011)$, although the same trend was recorded in both years (Fig. 4). In 2017, the average yield per plant for W4 to W8 inoculations and the healthy control was around $240 \mathrm{~g}$ compared with

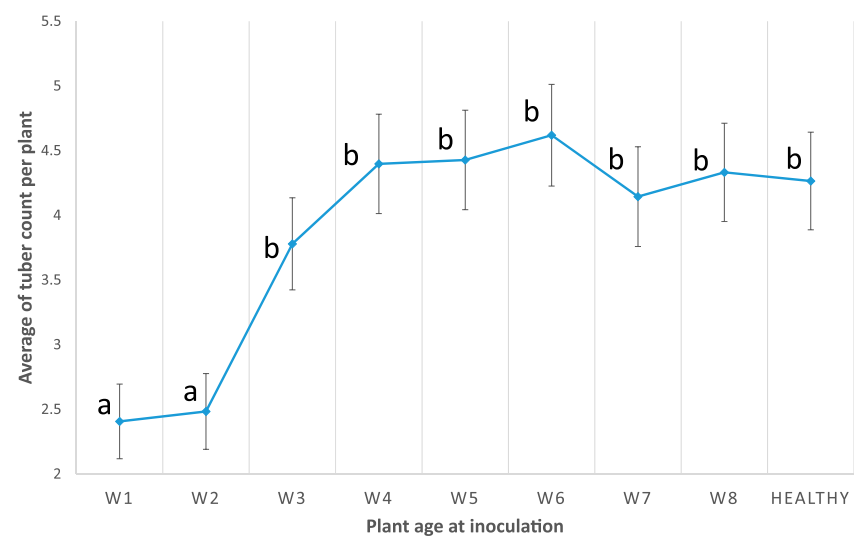

Fig. 3. The effects of the inoculation with the recombinant strain of potato virus $Y(P V Y)$, $P V Y^{\text {NTN }}$, at 8 consecutive weeks after transplanting (W1 to W8; $x$ axis) on the average of tuber counts per cultivar Yukon Gold plant ( $y$ axis) in greenhouse experiments in 2017 and 2018. Total numbers of tubers were recorded at harvest time for each plant and used in the analysis. Data were pool analyzed for 2017 and 2018 experiments using the GLIMMIX procedure (residual pseudo-likelihood). There were no significant effects of the year $(\operatorname{Pr}>F=0.5167)$ or the year $\times$ week of inoculation $(\operatorname{Pr}>F=0.8213)$. However, the effect of the week of inoculation was significant $(\operatorname{Pr}>F=0.0003)$. Values with the same lower case letters are not significantly different.

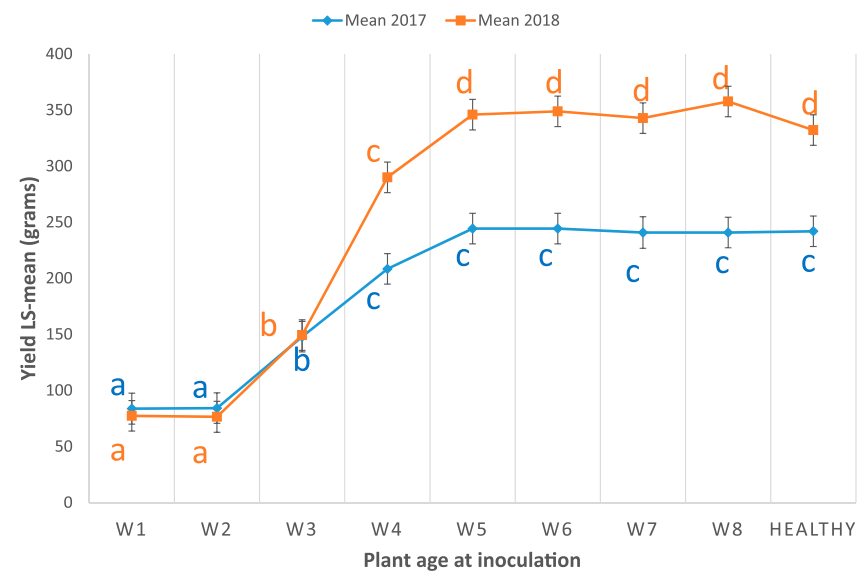

Fig. 4. The effects of the inoculation with the recombinant strain of potato virus $Y$ (PVY), PVY ${ }^{\text {NTN }}$, at 8 consecutive weeks after transplanting (W1 to W8; $x$ axis) on the average of tuber yield per cultivar Yukon Gold plant ( $y$ axis) in greenhouse experiments in 2017 and 2018 plotted separately. Data were analyzed using the GLIMMIX procedure (restricted maximum likelihood). Tuber yield was significantly affected by the plant age at inoculation $(\operatorname{Pr}>F=0.0001)$ and the year of experiment $(P r>F=0.0011)$, although the same trend was recorded in both years. Values with the same lower case letters are not significantly different. only $75 \mathrm{~g}$ for those of $\mathrm{W} 1$ and $\mathrm{W} 2$ inoculations (about 65\% less), whereas it reached about $80 \%$ yield reduction in 2018 for the same weeks of inoculation (Fig. 4). A pooled analysis of both years, 2017 and 2018, indicated significant differences for the tuber yield based on the plant age at inoculation. The yield for W1 and W2 inoculations was significantly lower than that of the W3 inoculation, which was significantly lower than that of the W4 inoculation. W4 tuber yield was lower than that from W5 to W8. No significant differences were recorded at W5 to W8 compared with the healthy control (Fig. 5).

The effects of plant age at inoculation on the occurrence and severity of PTNRD. At 1 month postharvest, about $100 \%$ of progeny tubers from plants inoculated at W1 and W2 showed necrotic ringspots in both years (Fig. 6 and Table 2). Tubers of W3 inoculation exhibited necrotic arcs and ringspots in 75 and $97 \%$ of total progeny tubers in 2017 and 2018, respectively. The incidence of tuber necrosis dropped to about 30 and $50 \%$ of total progeny tubers for W4 inoculation for the 2 years, respectively. Only about $4 \%$ of the tubers showed necrotic arcs in plants inoculated at W5, whereas at W6, about $5 \%$ of the tubers showed necrotic arcs and dark halos around tuber stolon ends in 2018, with none in 2017. No PTNRD was observed in tubers from plants inoculated at W7 and W8 as well as the healthy control tubers in either year (Table 2).

The number of rings/arcs was counted on each tuber as an indicator of the severity of PTNRD. The effect of the year or the year $x$ week interaction was not significant with $\operatorname{Pr}>F=0.1007$ and 0.1970 , respectively. However, the effect of plant age at the time of inoculation was evident with $P r>F \leq 0.0001$. Tubers from plants inoculated at $\mathrm{W} 1$ and $\mathrm{W} 2$ showed the most severe symptoms, with more than six necrotic rings per tuber; this number decreased significantly for plants inoculated at $\mathrm{W} 3$ to about necrotic 2.3 rings and further in W4 with an average of about 0.5 necrotic ring/arc per tuber (Fig. 7). Tubers from plants inoculated at W5 and W6 had a very low average number of necrotic arcs or dark halos around the stolon end, which was not significantly different from W7, W8, and the healthy control (Fig. 7).

The correlation between PTNRD and PVY primary and secondary infections. A high correlation between PVY primary systemic infection in 2018 and PTNRD symptoms on progeny tubers was observed $(P=0.0012 ; r=0.92)$. Similarly, high correlation between the PTNRD symptoms on seed tubers and the secondary systemic infection with PVY was observed in 2017 and $2018(P<$ $0.0001 ; r=0.97)$. In other words, PTNRD expression in Yukon Gold tubers represents a good indicator of a systemic PVY ${ }^{\mathrm{NTN}}$ infection.

\section{Discussion}

ARR in potato is a type of field resistance that was recognized and studied in Europe starting in the 1980s (Beemster 1976; Gibson

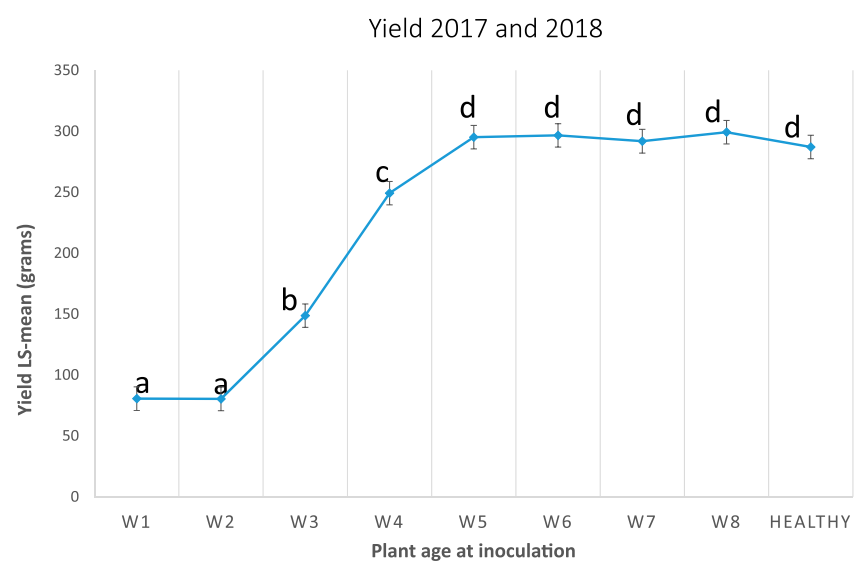

Fig. 5. A pooled analysis of 2017 and 2018 experiments showing the effects of the inoculation with the recombinant strain of potato virus $Y(P V Y), P V Y^{N T N}$, at 8 consecutive weeks after transplanting (W1 to W8; $x$ axis) on the average of yield per plant (grams; $y$ axis) of cultivar Yukon Gold plants in greenhouse experiments. Data were analyzed using the GLIMMIX procedure (restricted maximum likelihood). Values with the same lower case letters are not significantly different. 
1991; Sigvald 1985). At the time, it was named MPR and studied on European potato cultivars infected with the classical nonrecombinant PVY strains $\mathrm{PVY}^{\mathrm{O}}$ and $\mathrm{PVY}^{\mathrm{N}}$, demonstrating development of the MPR through reduced and blocked systemic movement of the virus and translocation into the progeny tubers starting at 3 to 4 weeks after emergence (Gibson 1991; Sigvald 1985). Similar effects were reported in a European cultivar Charlotte for two recombinant strains PVY ${ }^{\mathrm{N}-\mathrm{Wi}}$ and PVY ${ }^{\mathrm{NTN}}$ (Dupuis 2017).

In this study on a North American cultivar Yukon Gold and $\mathrm{PVY}^{\mathrm{NTN}}$, we observed an obvious ARR effect when the primary infection was confined to the inoculated leaves with impaired systemic movement starting from the W4 inoculation time point, when only $70 \%$ of the plants were PVY infected. From the W5 inoculation onward, the systemic movement of the virus was almost completely blocked, with very few plants found infected systemically (Fig. 2). This impairment of the systemic movement in the inoculated plants starting at the W4 inoculation generally correlated with the reduction of the secondary infection starting from W4 inoculation-derived tubers, which meant also an impairment in the translocation of the virus into tubers for plants inoculated starting at the W4 inoculation. However, later in the season (W4 to W8), a few plants tested negative for PVY in the upper noninoculated leaves (no systemic movement of the virus); nevertheless, they produced a small number of PVYinfected tubers, particularly at W4 to W6 inoculations. The same finding was reported by Jones and Vincent (2018): PVY was detected in progeny tubers without being detected in the foliage of primarily inoculated plants showing local HR. In the 2017 experiment, the upper noninoculated leaves of $13 \%$ of the plants of W4 to W8 were PVY negative but produced at least one PVY-positive tuber per plant. This number was reduced to $5 \%$ in 2018 for the same weeks of inoculation. Consistently, there were rare cases where late PVY infection may not lead to systemic spread of the virus in the foliage yet may result in production of PVY-infected tubers. Conversely, some upper noninoculated leaves of the plants inoculated later in the season (W4 to W8 inoculations) were found to be positive for PVY (systemically infected with PVY) but produced PVYnegative tubers (impairment of virus translocation to tubers). That was noted in three plants in W4 and W8 of 2017 (4\% of plants in W4 to W8) and two plants of W8 of 2018 (3\% of plants in W4 to W8), where the upper noninoculated leaves tested positive, but the two progeny tubers sampled were negative. On several occasions, 9 PVY-positive or PVY-negative plants of 150 plants at the W4 to
W8 inoculation time point for both 2017 and 2018 produced a mixture of infected and healthy tubers.

A $100 \%$ infection rate of Yukon Gold with $\mathrm{PVY}^{\mathrm{NTN}}$ reduced the average tuber counts by about $50 \%$ and the average yield by about $70 \%$ as seen in $\mathrm{W} 1$ and $\mathrm{W} 2$ inoculations. The per plant averages of tuber counts and yield were not affected by the late inoculation (W5 to W8) (Figs. 3, 4, 5, and 6). More specifically, the dramatic decline in the systemic movement of PVY ${ }^{\mathrm{NTN}}$ in potato inoculated at W4 to W8 (Fig. 2) was accompanied with a significant increase in the per plant average of tuber counts and yield compared with W1 and W2 inoculations, where $100 \%$ of PVY infection was recorded. Indeed, the tuber counts almost doubled in plants inoculated at W4 to W8 and equaled the healthy control. Systemic PVYNTN infection in plants of the W3 inoculation did not reduce the tuber counts significantly compared with the healthy control but resulted in significantly smaller tubers and lower average yield (Figs. 3, 4, 5, and 6). In 2018, an increase of about $100 \mathrm{~g}$ in the average yield was recorded for plants inoculated at W4 to W8 and the healthy control compared with the same treatments of the 2017 experiment. The greenhouse temperature records showed that, in 2018, the temperature fluctuated between 15 and $24^{\circ} \mathrm{C}$ during the night and day, respectively, whereas

Table 2. The percentage of tubers of the potato cultivar Yukon Gold displaying tuber necrotic ringspots at 1 month postharvest from plants inoculated with potato virus $\mathrm{Y}$ at 8 different consecutive weeks after transplanting and two seasons of greenhouse experiments in 2017 and 2018

\begin{tabular}{lrr}
\hline & \multicolumn{3}{c}{$\begin{array}{c}\text { Average of tubers with } \\
\text { PTNRD (\%) }\end{array}$} \\
\cline { 2 - 3 } Plant age $^{\mathbf{2}}$ inoculation & \\
\hline W1 & $\mathbf{2 0 1 7}$ & $\mathbf{2 0 1 8}$ \\
W2 & 99 & 97 \\
W3 & 100 & 99 \\
W4 & 75 & 97 \\
W5 & 29 & 51 \\
W6 & 5 & 4 \\
W7 & 0 & 6 \\
W8 & 0 & 0 \\
Healthy & 0 & 0 \\
\hline
\end{tabular}

${ }^{a} \mathrm{~W}$, week after transplanting at which the inoculation was carried out.

b PTNRD, potato tuber necrotic ringspot disease.
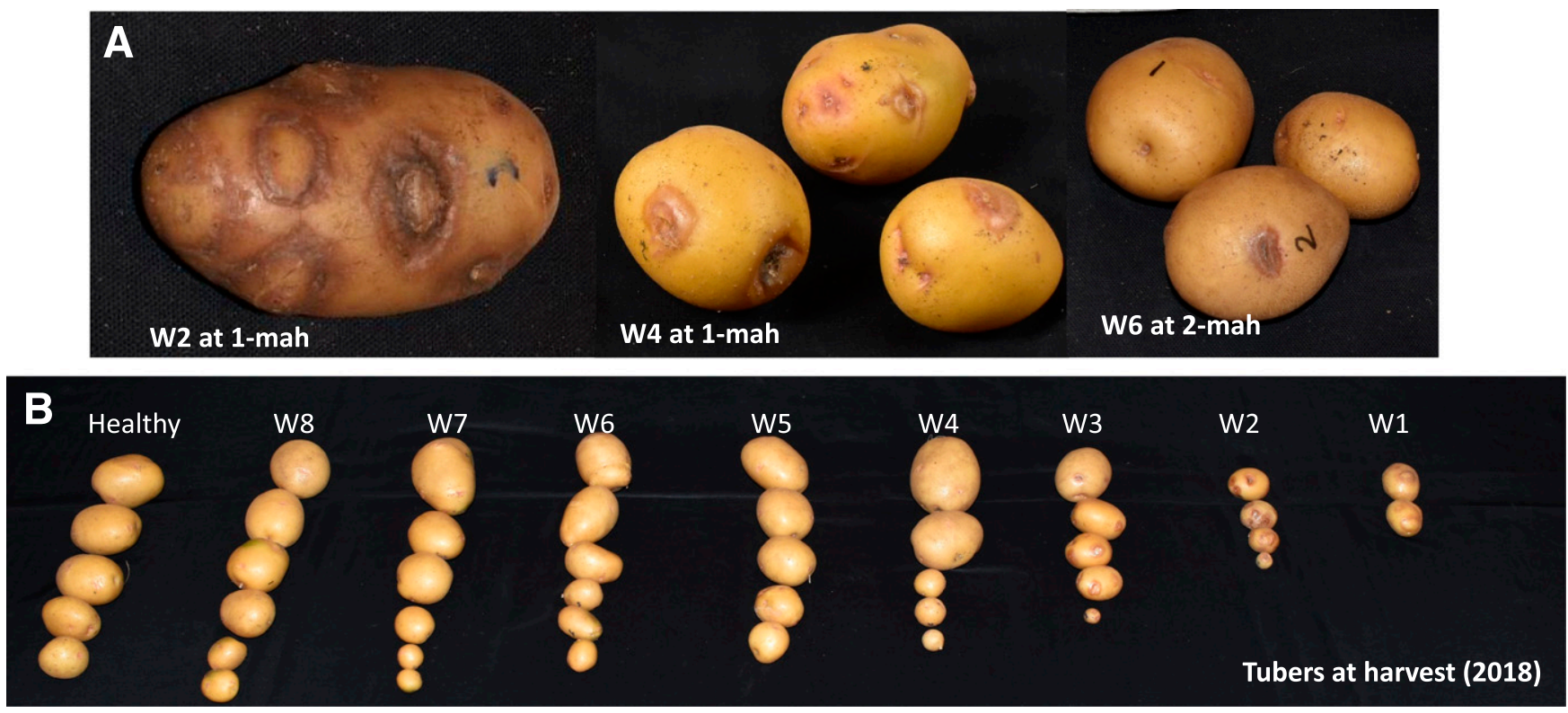

Fig. 6. Symptoms of potato tuber necrotic ringspot disease. A, Various severity levels of tuber necrosis associated with inoculation at different weeks after transplanting. B, Example of harvested tubers from plants inoculated at 8 consecutive weeks after transplanting in the greenhouse experiment of 2018. mah, months after harvest; W, weeks after transplanting when plants were inoculated with the recombinant strain of potato virus Y (PVY), PVYNTN. 
it ranged between 18 and $24^{\circ} \mathrm{C}$ during the night and day, respectively, in 2017. Previous reports showed that potato growth is affected by the day/night temperature (Benoit et al. 1986), and the day/night temperature fluctuation resulted in higher potato yield compared with a constant day/night temperature (Bennett et al. 1991). This may explain the higher yield in 2018, where the day/ night temperature fluctuation was higher than that of 2017. However, the effects of this day/night temperature were not noticeable in plants inoculated during the first 3 weeks posttransplantation, where PVY infection was $100 \%$ (Figs. 2 and 4). This suggests that a systemic PVY infection might limit the ability of potato plants to respond to day/night temperature fluctuation.

It is known that the symptoms of PTNRD progress during storage (Le Romancer and Nedellec 1997); hence, tubers were kept at room temperature $\left(20^{\circ} \mathrm{C}\right)$ and scored for incidence and severity of PTNRD at 1 month postharvest. High correlation was observed between the incidence of PTNRD and the primary and secondary systemic PVYNTN infection in Yukon Gold. Therefore, PVYNTN infection not only reduced plant yield in Yukon Gold but also, dramatically affected quality of tubers, rendering them unmarketable (Figs. 6 and 7), which increased the significance of the PVY control early in the growing season.

Yukon Gold has the $N z_{t b r}$ resistance gene that triggers HR on the infection with PVY ${ }^{\text {NTN }}$ (Chikh-Ali et al. 2014; Kerlan et al. 2011). Inoculated leaves exhibited HR regardless of the plant age, and the virus was readily detected in those inoculated leaves but not in the upper noninoculated leaves of plants from late inoculations (W5 to W8). This indicates that the effectiveness of HR in restricting the systemic movement of PVYNTN has increased as plants aged. The relation between the HR and ARR and their roles in restriction of the systemic movement of PVYNTN require additional studies on potato cultivars lacking the $N z_{t b r}$ gene. Previous studies, however, demonstrated ARR in cultivar-strain combinations where no specific $N$ gene was known to be expressed. For instance, Gibson (1991) reported mature resistance in cultivars King Edward and Maris Piper against $\mathrm{PVY}^{\mathrm{O}}$ and $\mathrm{PVY}^{\mathrm{N}}$, although no strain-specific $N$ resistance genes were reported in these two cultivars eliciting HR to these two strains (Gibson 1991; Jones 1990). In the case of another potyvirus, bean common mosaic necrosis virus (BCMNV), two types of the resistance in common bean were found uncoupled (the HR type expressed by the $I$ gene and the recessive resistance restricting systemic movement of BCMNV) and expressed by the $b c-1$ gene (Feng et al. 2017).

From a practical standpoint, the ARR may have great promise in the control of PVY for both seed and commercial potato production

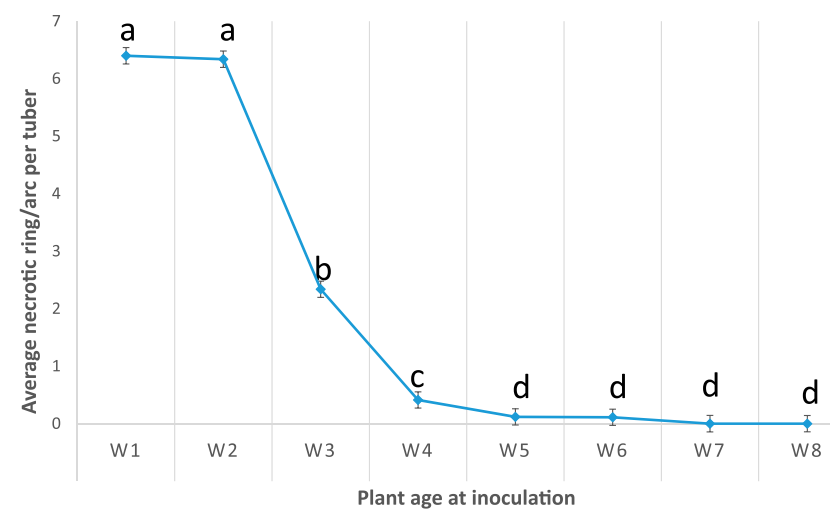

Fig. 7. The effects of the inoculation with the recombinant strain of potato virus $Y$ (PVY), PVY ${ }^{\text {NTN }}$, at 8 consecutive weeks after transplanting (W1 to W8; $x$ axis) on the severity of potato tuber necrotic ringspot disease (PTNRD) on tubers of cultivar Yukon Gold plants in greenhouse experiments in 2017 and 2018 combined. The PTNRD severity was scaled on each tuber by counting the numbers of necrotic rings and arcs at 1 month postharvest. Data were analyzed using the GLIMMIX procedure (restricted maximum likelihood). The effects of the year or the year $x$ week interaction were not significant $(P r>F=0.1007$ and 0.1970 , respectively). However, the effect of plant age at the time of inoculation was evident with $\operatorname{Pr}>$ $F \leq 0.0001$. Values with the same lower case letters are not significantly different.
(Beemster 1976; Gibson 1991; Sigvald 1985). The observed ARR in Yukon Gold was established within the first 3 weeks posttransplantation and maintained a robust, almost complete control of the PVY ${ }^{\text {NTN }}$ infection starting from W5 inoculation. Consequently, if applicable to other cultivar-strain combinations and in the absence of a massive, early-season infestation with PVY, ARR provides sufficient protection to the crop, and commercial potato producers may be assured that the damage to the potato yields and tuber quality caused by the late season PVY infection should be negligible as long as they use high-quality certified seed potato. For seed potato producers, however, this study points at the early season as a critical timeframe for the efficient protection of potato crops from PVY infection. If such control early in the season is provided, it would greatly reduce the number of infection sources in the field available for aphid transmission later in the season and reduce the overall PVY translocation into progeny tubers in otherwise asymptomatic plants missed during visual summer inspections. To assess the value of ARR to control PVY, additional work on other main PVY strains, such as PVY ${ }^{\mathrm{N}-\mathrm{Wi}}$, and main potato cultivars in North America will be needed.

\section{Acknowledgments}

We thank J. Chojnacky for laboratory and greenhouse help and J. Durrin for providing potato plantlets.

\section{Literature Cited}

Asama, K., Ito, H., Murakami, N., and Itoh, T. 1982. New potato variety "Konafubuki." Bull Hokkaido Prefer. Agr Exp Stn 48:75-84.

Baldauf, P. M., Gray, S. M., and Perry, K. L. 2006. Biological and serological properties of Potato virus $Y$ isolates in northeastern United States potato. Plant Dis. 90:559-566.

Beczner, L., Horvath, J., Romhanyi, I., and Forster, H. 1984. Studies on the etiology of tuber necrotic ringspot disease in potato. Potato Res. 27:339-352.

Beemster, A. B. R. 1976. Translocation of the potato viruses yn and yo in some potato varieties. Potato Res. 19:169-172.

Bennett, S. M., Tibbitts, T. W., and Cao, W. 1991. Diurnal temperature fluctuation effects on potatoes grown with $12 \mathrm{hr}$ photoperiods. Am. Potato J. 68:81-86.

Benoit, G. R., Grant, W. J., and Devine, O. J. 1986. Potato top growth as influenced by day-night temperature differences. Agron. J. 78:264-269.

Chikh-Ali, M., Gray, S. M., and Karasev, A. V. 2013a. An improved multiplex IC-RTPCR assay distinguishes nine strains of Potato virus Y. Plant Dis. 97:1370-1374.

Chikh-Ali, M., Karasev, A. V., Furutani, N., Taniguchi, M., Kano, Y., Sato, M., Natsuaki, T., and Maoka, T. 2013b. Occurrence of Potato virus $Y$ strain $\mathrm{PVY}^{\mathrm{NTN}}$ in foundation seed potatoes in Japan, and screening for symptoms Japanese potato cultivars. Plant Pathol. 62:1157-1165.

Chikh-Ali, M., Rowley, J. S., Kuhl, J., Gray, S. M., and Karasev, A. V. 2014. Evidence of a monogenic nature of the $N z$ gene conferring resistance against Potato virus $Y$ strain $Z\left(\mathrm{PVY}^{\mathrm{Z}}\right)$ in potato. Am. J. Potato Res. 91:649-654.

Cockerham, G. 1970. Genetic studies on resistance to potato viruses X and Y. Heredity 25:309-348.

Crosslin, J. M., Hamm, P. B., Eastwell, K. C., Thornton, R. E., Brown, C. R., Corsini, D., Shiel, P. J., and Berger, P. H. 2002. First report of the necrotic strain of Potato virus $Y\left(\mathrm{PVY}^{\mathrm{N}}\right)$ on potatoes in the northwestern United States. Plant Dis. 86:1177.

Davidson, T. M. W. 1980. Breeding for resistance to virus disease of the potato (Solanum tuberosum) at the Scottish Plant Breeding Station. Pages 100-108 in: Scottish Plant Breeding Station Annual Report for 1979-1980, Pentlandfield, Scotland.

de Bokx, J. A., and Huttinga, H. 1981. Potato virus Y. Descriptions of Plant Viruses No. 242. Commonw. Mycol. Inst./Assoc. Appl. Biol., Kew, England. http://www.dpvweb.net/dpv/showdpv.php?dpvno=242.

Develey-Rivière, M. P., and Galiana, E. 2007. Resistance to pathogens and host developmental stage: A multifaceted relationship within the plant kingdom. New Phytol. 175:405-416.

Dupuis, B. 2017. The movement of Potato virus $Y$ (PVY) in the vascular system of potato plants. Eur. J. Plant Pathol. 147:365-373.

Dupuis, B., Bragard, C., and Schumpp, O. 2019. Resistance of potato cultivars as a determinant factor of Potato virus Y (PVY) epidemiology. Potato Res. 62: 123-138.

Feng, X., Guzmán, P., Myers, J. R., and Karasev, A. V. 2017. Resistance to Bean common mosaic necrosis virus conferred by the $b c-1$ gene affects systemic spread of the virus in common bean. Phytopathology 107:893-900.

Frost, K. E., Groves, R. L., and Charkowski, A. O. 2013. Integrated control of potato pathogens through seed potato certification and provision of clean seed potatoes. Plant Dis. 97:1268-1280.

Funke, C. N., Nikolaeva, O. V., Green, K. J., Tran, L. T., Chikh Ali, M., QuinteroFerrer, A., Cating, R., Frost, K. E., Hamm, P. B., Olsen, N., Pavek, M. J., Gray, S. M., Crosslin, J. M., and Karasev, A. V. 2017. Strain-specific resistance to Potato virus $Y$ (PVY) in potato and its effect on the relative abundance of PVY strains in commercial potato fields. Plant Dis. 101:20-28. 
Gibson, R. W. 1991. The development of mature plant-resistance in four potato cultivars against aphid-inoculated potato virus $\mathrm{Y}^{\mathrm{O}}$ and $\mathrm{Y}^{\mathrm{N}}$ in four potato cultivars. Potato Res. 34:205-210.

Gray, S., De Boer, S., Lorenzen, J., Karasev, A., Whitworth, J., Nolte, P., Singh, R., Boucher, A., and Xu, H. M. 2010. Potato virus Y: An evolving concern for potato crops in the United States and Canada. Plant Dis. 94:1384-1397.

Gray, S., and Power, A. G. 2018. Anthropogenic influences on emergence of vector-borne plant viruses: The persistent problem of Potato virus Y. Curr. Opin. Virol. 33:177-183.

Green, K. J., Brown, C. J., and Karasev, A. V. 2018. Genetic diversity of potato virus Y (PVY): Sequence analyses reveal ten novel PVY recombinant structures. Arch. Virol. 163:23-32.

Hu, L., and Yang, L. 2019. Time to fight: Molecular mechanisms of age-related resistance. Phytopathology 109:1500-1508.

Jones, R. A. C. 1990. Strain group specific and virus specific hypersensitive reactions to infection with potyviruses in potato cultivars. Ann. Appl. Biol. 117:93-105.

Jones, R. A. C., and Vincent, S. 2018. Strain-specific hypersensitive and extreme resistance phenotypes elicited by Potato virus Y among 39 potato cultivars released in three world regions over a 117 year period. Plant Dis. 102:185-196.

Karasev, A. V., and Gray, S. M. 2013. Continuous and emerging challenges of Potato virus $Y$ in potato. Annu. Rev. Phytopathol. 51:571-586.

Karasev, A. V., Meacham, T., Hu, X., Whitworth, J., Gray, S. M., Olsen, N., and Nolte, P. 2008. Identification of Potato virus Y strains associated with tuber damage during a recent virus outbreak in potato in Idaho. Plant Dis. 92:1371.

Karasev, A. V., Nikolaeva, O. V., Hu, X., Sielaff, Z., Whitworth, J., Lorenzen, J. H., and Gray, S. M. 2010. Serological properties of ordinary and necrotic isolates of Potato virus Y: A case study of PVYN misidentification. Am. J. Pot. Res. 87:1-9.

Kehoe, M. A., and Jones, R. A. C. 2016. Potato virus $Y$ strain nomenclature: Lessons from comparing isolates obtained over a 73-year period. Plant Pathol. 65:322-333.

Kerlan, C., Nikolaeva, O. V., Hu, X., Meacham, T., Gray, S. M., and Karasev, A. V. 2011. Identification of the molecular make-up of the Potato virus $Y$

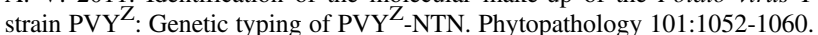

Kus, J. V., Zaton, K., Sarkar, R., and Cameron, R. K. 2002. Age-related resistance in Arabidopsis is a developmentally regulated defense response to Pseudomonas syringae. Plant Cell 14:479-490.

Le Romancer, M., Kerlan, C., and Nedellec, M. 1994. Biological characterization of various geographical isolates of Potato virus $Y$ including superficial necrosis on potato tubers. Plant Pathol. 43:138-144.

Le Romancer, M., and Nedelec, M. 1997. Effect of plant genotype, virus isolate and temperature on the expression of the potato tuber necrotic ringspot disease (PTNRD). Plant Pathol. 46:104-111.

Liu, Y., Qi, A., and Khan, M. F. R. 2019. Age-dependent resistance to Rhizoctonia solani in sugar beet. Plant Dis. 103:2322-2329.

Lorenzen, J., Nolte, P., Martin, D., Pasche, J. S., and Gudmestad, N. C. 2008. NE-11 represents a new strain variant class of Potato virus $Y$. Arch. Virol. 153:517-525.

MacKenzie, T. D. B., Lavoie, J., Nie, X., and Singh, M. 2018. Differential spread of Potato virus $Y$ (PVY) strains $\mathrm{O}, \mathrm{N}: \mathrm{O}$ and $\mathrm{NTN}$ in the field: Implications for the rise of recombinant PVY strains in New Brunswick, Canada. Am. J. Potato Res. 95:301-310

MacKenzie, T. D. B., Nie, X., Bisht, V., and Singh, M. 2019. Proliferation of recombinant PVY strains in two potato producing regions of Canada, and symptom expression in 30 important potato varieties with different PVY strains. Plant Dis. 103:2221-2230.

McDonald, J. G., and Singh, R. P. 1996. Host range, symptomology, and serology of isolates of potato virus $\mathrm{Y}$ (PVY) that share properties with both the $\mathrm{PVY}^{\mathrm{N}}$ and $\mathrm{PVY} \mathrm{O}^{\mathrm{O}}$ strain groups. Am. Potato J. 73:309-315.
Munoz, F. J., Plaisted, R. L., and Thurston, H. D. 1975. Resistance to potato virus $\mathrm{Y}$ in Solanum tuberosum ssp. andigena. Am. Potato J. 52:107-115.

Nikolaeva, O. V., Roop, D. J., Galvino-Costa, S. B. F., dos Reis Figueira, A., Gray, S. M., and Karasev, A. V. 2012. Epitope mapping for monoclonal antibodies recognizing tuber necrotic isolates of Potato Virus Y. Am. J. Potato Res. 89 121-128.

Nolte, P., Whitworth, J. L., Thornton, M. K., and McIntosh, C. S. 2004. Effect of seedborne Potato virus $Y$ on performance of Russet Burbank, Russet Norkotah, and Shepody potato. Plant Dis. 88:248-252.

Novy, R. G., Whitworth, J. L., Stark, J. C., Schneider, B. L., Knowles, N. R., Pavek, M. J., Knowles, L. O., Charlton, B. A., Sathuvalli, V., Yilma, S., Brown, C. R., Thornton, M., Brandt, T. L., and Olsen, N. 2017. Payette Russet: A dual-purpose potato cultivar with cold-sweetening resistance, low acrylamide formation, and resistance to late blight and potato virus Y. Am. J. Potato Res. 94:38-53.

Panter, S. N., and Jones, D. A. 2002. Age-related resistance to plant pathogens. Adv. Bot. Res. 38:251-280.

Piche, L. M., Singh, R. P., Nie, X., and Gudmestad, N. C. 2004. Diversity among PVY field isolates obtained from potatoes grown in the United States. Phytopathol. 94:1368-1375.

Quenouille, J., Vassilakos, N., and Moury, B. 2013. Potato virus Y: a major crop pathogen that has provided major insights into the evolution of viral pathogenicity. Mol. Plant Pathol. 14:439-452.

Rosenman, J., McIntosh, C., Nolte, P., and Aryal, G. 2019. Planting a problem-examining the spread of seed-borne Potato virus Y. Plant Dis. 103: 2179-2183

Rowley, J. S., Gray, S. M., and Karasev, A. V. 2015. Screening potato cultivars for new sources of resistance to Potato virus $Y$. Am. J. Potato Res. 92:38-48.

Shibata, Y., Kawakita, K., and Takemoto, D. 2010. Age-related resistance of Nicotiana benthamiana against hemibiotrophic pathogen Phytophthora infestans requires both ethylene- and salicylic acid-mediated signaling pathways. Mol. Plant-Micr. Interact. 23:1130-1142.

Sigvald, R. 1985. Mature-plant resistance of potato plants against potato virus $\mathrm{Y}^{\mathrm{O}}$ $\left(\mathrm{PVY}^{\mathrm{O}}\right.$ ). Potato Res. 28:135-143

Singh, R. P., Valkonen, J. P. T., Gray, S. M., Boonham, N., Jones, R. A. C., Kerlan, C., and Schubert, J. 2008. The naming of Potato virus $Y$ strains infecting potato. Arch. Virol. 153:1-13.

Solomon-Blackburn, R. M., and Barker, H. 2001a. A review of host major-gene resistance to potato viruses $\mathrm{X}, \mathrm{Y}, \mathrm{A}$ and $\mathrm{V}$ in potato: Genes, genetics and mapped locations. Heredity 86:8-16.

Solomon-Blackburn, R. M., and Barker, H. 2001b. Breeding virus resistant potatoes (Solanum tuberosum): A review of traditional and molecular approaches. Heredity 86:17-35.

Valkonen, J. P. T. 1994. Natural genes and mechanisms for resistance to viruses in cultivated and wild potato species (Solanum spp.). Plant Breed. 112:1-16.

Valkonen, J. P. T., Jones, R. A. C., Slack, S. A., and Watanabe, K. N. 1996. Resistance specificities to viruses in potato: Standardization of nomenclature. Plant Breed. 115:433-438.

van den Heuvel, J. F. J. M., Van der Vlugt, R. A. A., Verbeek, M., De Haan, P. T., and Huttinga, H. 1994. Characteristics of a resistance-breaking isolate of potato virus $\mathrm{Y}$ causing potato tuber necrotic ringspot disease. Eur. J. Plant Pathol. 100: 347-356.

Wilson, D. C., Kempthorne, C. J., Carella, P., Liscombe, D. K., and Cameron, R. K. 2017. Age-related resistance in Arabidopsis thaliana involves the MADS-domain transcription factor SHORT VEGETATIVE PHASE and direct action of salicylic acid on Pseudomonas syringae. Mol. Plant-Microbe Interact. 30:919-929. 